\title{
CUITLAHUAC. LA VIDA EN UN ENTORNO LACUSTRE (SIGLOS XVI-XVIII)
}

Fecha de recepción: 26.06 .2020

Resumen: Cuitlahuac, la actual Tláhuac, al sur de la Ciudad de México, fue un antiguo señorío asentado en un islote entre los lagos de Xochimilco y Chalco. Ese entorno determinó la vida de sus habitantes, cuya actividad predominante fue la pesca, desde los orígenes de su historia hasta bien entrado el periodo colonial. Fueron las agresiones medioambientales de finales del siglo XIX y principios del siglo XX las que acabaron por transformar significativamente su entorno y medio de vida. Hoy día, Tláhuac se erige como uno de los pueblos originarios de la Ciudad de México que, acosado por la mancha urbana de esta megalópolis, lucha por preservar algunas de sus tradiciones de hondas raíces históricas. El objetivo de este trabajo es ofrecer un panorama de la vida de los pobladores de Cuitlahuac durante la Colonia, en especial en su relación con el agua. Por ello nos centraremos en dos aspectos fundamentales de su economía de subsistencia: a) la pesca con la que sus habitantes se alimentaban y comerciaban; b) la renta de sus ciénagas para el pastoreo de las vacas de los abastecedores de carne de la Ciudad de México. Lo haremos acompañados de algunos casos de estudio que nos permitirán conocer la regulación colonial que existía en torno a la laguna, los contratos de arrendamiento de sus aguas, sus incumplimientos, las disputas que ocasionaban, y cómo estas se dirimían.

Palabras clave: Cuitlahuac, Tláhuac, historia colonial, agua, ciénagas, pesca, zacate

Title: Cuitlahuac. Life in a Lake Environment (16th-18th Centuries)

Abstract: Cuitlahuac, present-day Tláhuac in southern Mexico City, was an ancient realm situated on an island separating the lakes of Xochimilco and Chalco. This habitat determined the lives of its inhabitants since its foundation until well into the colonial period, as their main economic activity was fishing. However, at the end of the nineteenth and beginning of the twentieth century the damage made to the environment meant significant transformations to this habitat and therewith to the means of life in the region. Today, Tláhuac is known as one of the autochthonous towns (pueblos originarios) of Mexico City, which, beset by the ever-growing urban sprawl, is fighting to conserve some of the traditions emerging from its profound historical roots. The objective of this article is to offer a panoramic view of Cuitlahuac people during the colonial period and, particularly, of its relationship with the lakes. The focus will be two fundamental aspects of its subsistence economy: a) the fishing, activity that provided the inhabitants with food and merchandise; b) the rental of swamps for the grazing cows that provided meat to Mexico City. A number of legal cases will be discussed in order to show the colonial regulations that existed 
concerning the lakes: the rental contracts of its waters that were written up, as well as how these were breached, the consequent disputes that arose, and how these were settled.

Key words: Cuitlahuac, Tláhuac, colonial history, lakes, swamps, fishing

\section{INTRODUCCIÓN}

Cuitlahuac, hoy San Pedro Tláhuac, era un antiguo señorío lacustre ubicado en el sur de la cuenca de México, junto a otros importantes centros políticos como Xochimilco, Culhuacan y Chalco (Fig. 1). Según las antiguas crónicas, los cuitlahuacas eran gente de filiación chichimeca que llegó al área en el marco de las oleadas migratorias de varios pueblos que poblaron el centro de México. La fecha de su llegada no es del todo clara, pero se infiere que lo hicieron hacia el 1250 d.C. ${ }^{1}$.

Los cuitlahuacas venían guiados por su dios Iztacmixcoatl (el Mixcoatl blanco), también conocido como Mixcoatl "el joven" o el menor de los Mixcoatl (Mixcohuaxocoyotl). Fue él quien les señaló el lugar donde establecerse, a saber, un islote en medio del lago de Chalco que dividió en cuatro barrios: Tiçic, Teopancalcan, Tecpan y Atenchicalcan (Anales de Cuauhtitlan 1992: párr. 218), de los cuales todavía hay vestigios en documentos y mapas del siglo XVIII (Fig. 2) ${ }^{2}$. No cabe duda de que ese medio ambiente, en el que hasta hace relativamente poco predominaban lagos, lagunas y pantanos, determinó la vida de sus habitantes.

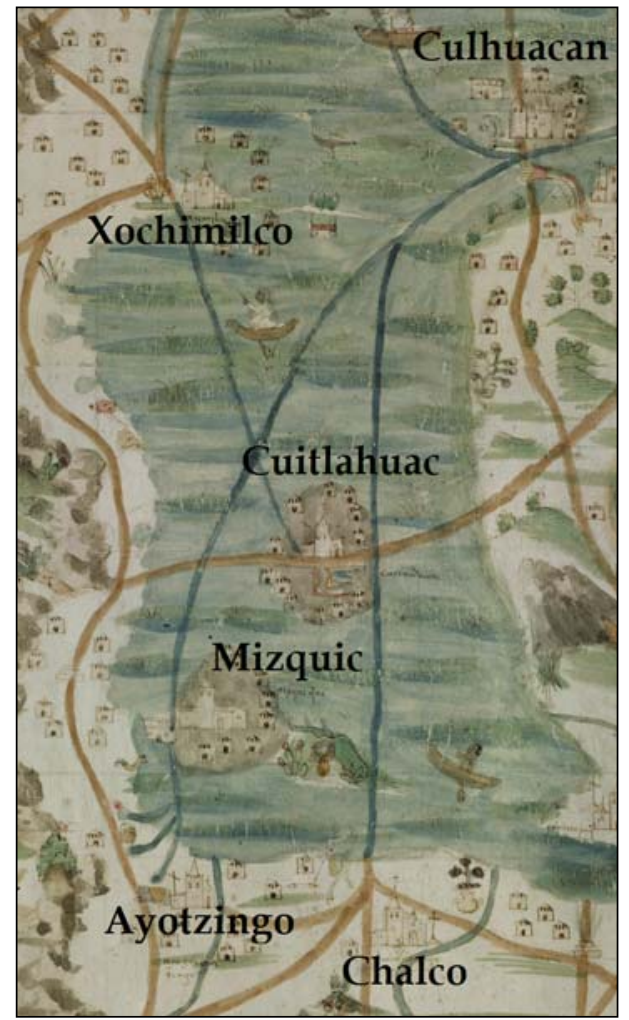

Fig. 1 Las islas de Cuitlahuac y Mizquic. Mapa de Santa Cruz (detalle), Universidad de Uppsala, Suecia.

\footnotetext{
$1 \quad$ Estas migraciones se iniciaron a finales del siglo XI y principios del siglo XII. De las fuentes históricas se infiere que los tenochcas fueron los últimos en llegar -hacia 1300 d.C.-, aunque fundaron su capital en 1325 d.C.

2 Para Iztacmixcoatl como dios de los cuitlahuacas, cf. Anales de Cuauhtitlan (1992: párr. 84). Sobre la importancia de esta deidad en la Tira de la Peregrinación, consúltese el trabajo de Castañeda de la Paz (2018: 61-74). La división de Cuitlahuac en cuatro partes se halla en Anales de Cuauhtitlan (1992: párrs. 141, 222). Para esa misma división en el siglo XVIII, $c f$. AGN (Tierras, vol. 1631, exp. 1, cuad. 8, fol. 30r) y el mapa catalogado como Ms. Mexicain 152 en la Biblioteca nacional de Francia (BnF).
} 


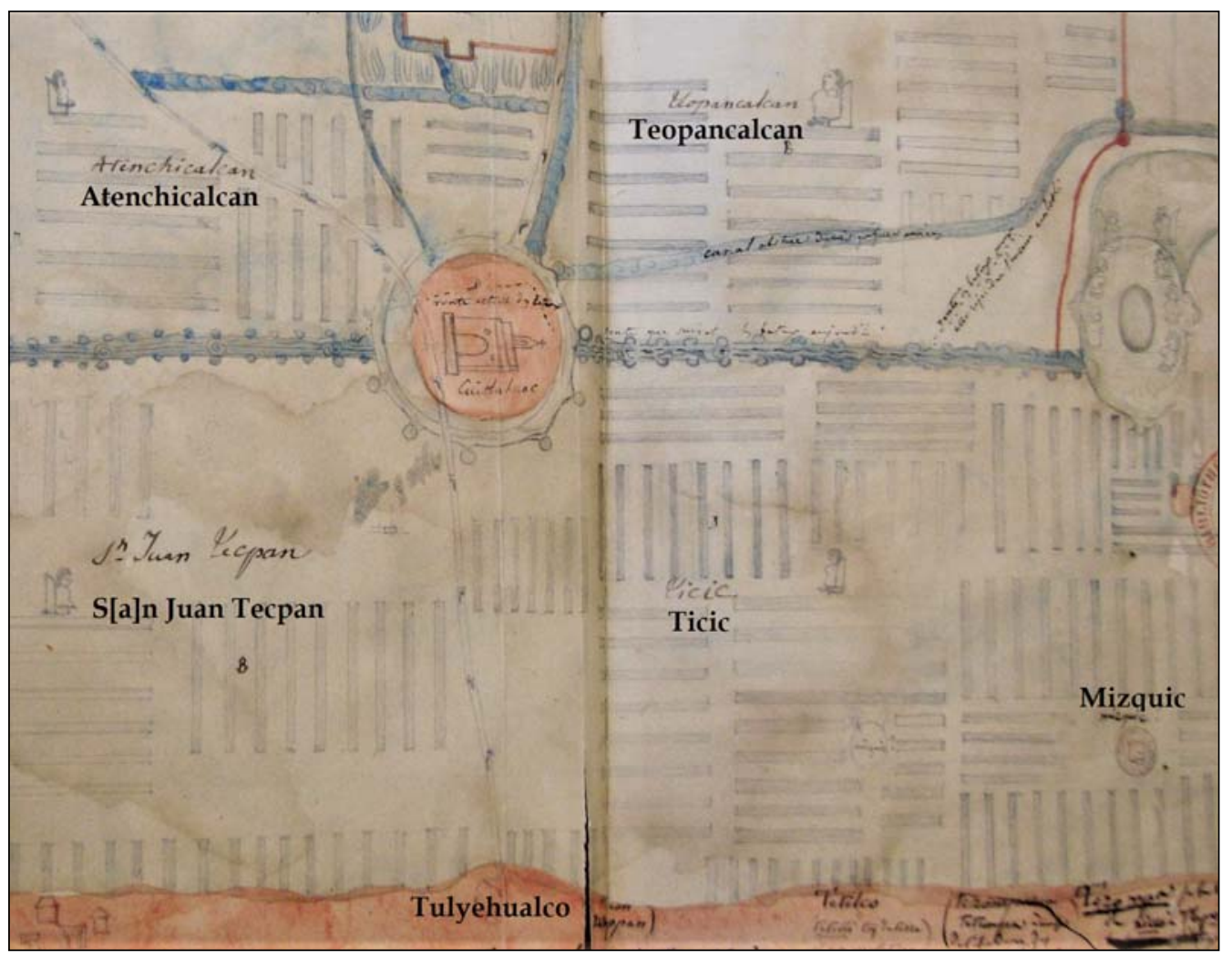

Fig. 2 Cuitlahuac y sus cuatro barrios (detalle). Ms. Mex. 152, BnF.

La cuenca de México, como varios autores han señalado, se hallaba rodeada de montañas que no permitían el desagüe natural de los cuerpos de agua que albergaba. La profundidad de estos era poca y no sobrepasaba los 2,5 o 3 metros. Un complejo sistema hidráulico evitaba que en tiempos de sequía la Ciudad de México se inundara con las aguas de los lagos del sur, ubicados a mayor altura, a la vez que no permitía que las aguas saladas del noroeste de la cuenca se entremezclaran con las aguas dulces de los lagos meridionales en época de lluvias. El lago predominante era el de Texcoco, al norte del cual estaban el de Zumpango y el de Xaltocan, así llamados por los señoríos allí ubicados. Al sur estaba el lago de Xochimilco y Chalco, en cuyas aguas estaba la isla de Cuitlahuac, que quedó comunicada con tierra firme gracias a un dique-calzada que dividía ambos cuerpos de agua, en cuyas orillas estaban los señoríos de Chalco y Xochimilco (Fig. 3).

Ahora bien, a pesar de las obras hidráulicas que se iniciaron a principios del siglo XVII, por ese afán de los españoles de drenar los lagos para evitar las inundaciones que afectaban a la Ciudad de México (asentada en el lago de Texcoco), y por la creencia de que sus aguas eran fuente de infecciones (cf. Musset 1992: 32), es sorprendente que los habitantes de Cuitlahuac y de otros pueblos ribereños hayan logrado vivir de la pesca, su principal medio de subsistencia, hasta hace relativamente poco. Pero si bien es cierto que la mano del hombre no ha dejado de alterar este ecosistema, también es verdad que 


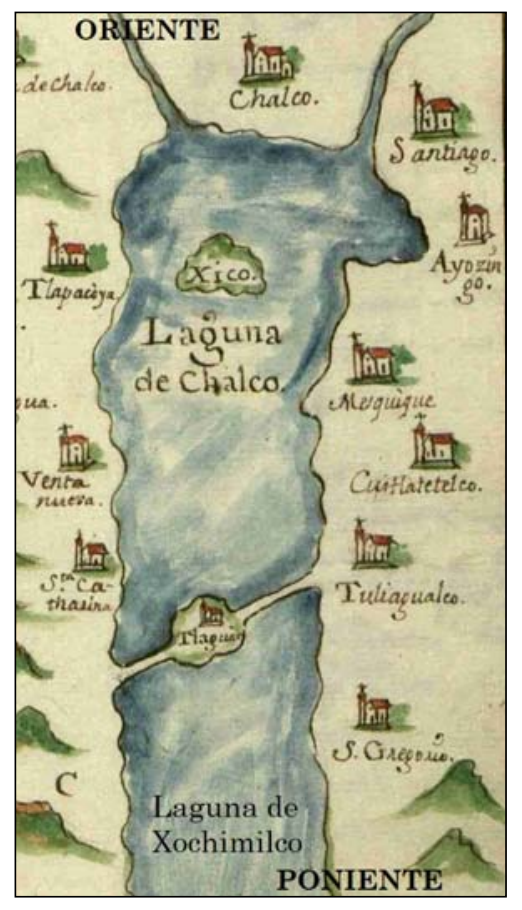

Fig. 3 La isla de Cuitlahuac entre los lagos de Chalco y Xochimilco (detalle). AGN, Desagüe, vol. 17, exp. 10, fol. 224r (Mapoteca núm. 21).

no fue hasta finales del siglo XIX cuando los lagos de Chalco y Xochimilco se vieron seriamente afectados por la construcción de canales para drenar el sur de la cuenca, así como por la desviación de los ríos que alimentaba sus lagos. Un desastre ambiental al que se sumó el de principios del siglo XX, cuando se tomó la decisión de captar el agua de sus manantiales para surtir de agua potable a la Ciudad de México, agotando las fuentes ( $c f$. Jiménez Osornio y Gomez-Pompa 1993: 259, Narchi y Canabal Cristiani 2015: 94). Debido a que Cuitlahuac estaba asentada en el centro del antiguo lecho del lago, es por lo que Sanders señaló que fue duramente golpeada por esa desecación, aunque su situación mejoró, en parte, gracias al cultivo de los ejidos en ese antiguo lecho (1993: 137). Lo anterior es lo que provocó que, con el paso de los siglos, algunos de los lagos de la cuenca de México acabaran convertidos en charcas (como sucedió con el de Chalco y Xochimilco), mientras que otros lo hicieron en pantanos, prados y bosques (Losada et al. 2017: 20). Es lo que veremos en este trabajo, en el que nos remontaremos al periodo colonial y nos centraremos en un aspecto fundamental de su economía de subsistencia: la pesca y el negocio del zacate de sus ciénagas a partir de la información consultada en varios documentos del Archivo General de la Nación (AGN) y el apoyo de algunos mapas.

No obstante, y para terminar, solo me queda añadir que hoy día Tláhuac es uno de los pueblos originarios de la Ciudad de México. Es decir, un lugar con hondas raíces históricas que sigue asentado en un territorio ancestral, cuya población conserva su identidad étnica a partir de la preservación de fiestas, modos de producción, interacción con el medio ambiente y fuerzas de la naturaleza, etc. (cf. Medina Hernández 2006: 85, 2007: 9-22; Losada et al. 2017: 18). Es lo que ha llevado a su población a reivindicar su territorio, los derechos a sus particularidades culturales y a tener una presentación política en las instancias del gobierno (Medina Hernández 2006: 85, 2007: 9).

\section{LOS PROBLEMAS DE UNA CABECERA ASENTADA EN UNA ISLA}

En el siglo XVI, la ribera de Cuitlahuac estaba salpicada de varias estancias, entre las que se encontraban Santiago Zapotitlan, Santa Bárbara, Santa Ana, San Pablo, San Antonio, San Francisco Tlaltengo, la Exaltación de la Santa Cruz Aguayocan y Santa Catari- 
na Mártir (hoy Santa Catarina Yecahuizotl), las cuales fueron congregadas en los primeros meses de $1603^{3}$. El objetivo de reunir a los habitantes de todas estas estancias tan dispersas era la mejor administración de la doctrina, motivo por el que el juez de la demarcación consideró que todas ellas debían congregarse en San Francisco Tlaltengo, con el objetivo de convertir esta estancia en pueblo de visita o cabeza de doctrina ${ }^{4}$. Fernández Christlieb y Urquijo Torres señalan que la elección de los asentamientos de las nuevas congregacio-

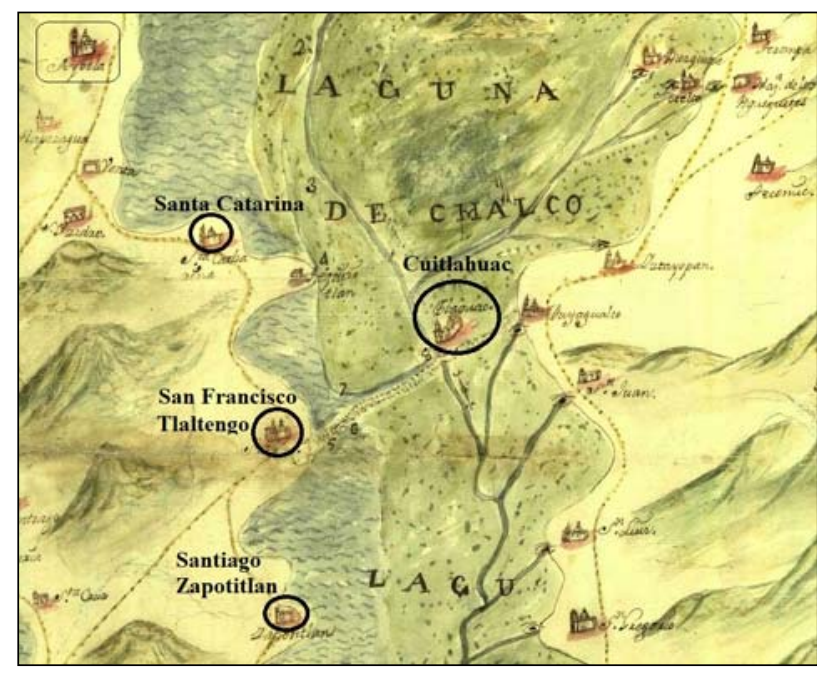

Fig. 4 Cuitlahuac y sus pueblos: Santiago Zapotitlan, San Francisco Tlaltengo y Santa Catarina Mártir (detalle). AGN, Desagüe, vol. 18, exp. 3, fol. 33r (Mapoteca núm. 22).

nes venía determinada por las concepciones europeas, basadas en las de la antigüedad clásica, que requerían que este fuera preferentemente llano y de fácil acceso, con un río contiguo (2006: 148-149). La elección de San Francisco Tlaltengo, sin embargo, no fue del agrado de todos porque decían que se les alejaba mucho de la laguna, donde la población tenía sus canoas y sementeras, razón por la cual era difícil acudir a la Ciudad de México a cumplir con el tributo ${ }^{5}$. Por esto, llama la atención que fueran sus habitantes quienes ofrecieran una mejor solución al presentar los beneficios de congregarse en Santiago Zapotitlan, argumentando que estaba mucho más cerca de la laguna ${ }^{6}$. Una propuesta que fue aceptada sin mayor discusión por lo razonable que resultaba el emplazamiento. De esta forma, Santa Bárbara, Santa Ana, San Pablo y San Antonio se congregaron en dicho pueblo, mientras que la Exaltación de la Cruz Aguayocan lo hizo en Tlaltengo, convirtiéndose ambos en visitas de doctrina y, a la vez, en pueblos sujetos de Cuitlahuac, junto con Santa Catarina Mártir (Fig. 4). En el otro lado de la isla, entre el pueblo de Tulyehualco y Mizquic, había otra estancia dependiente de Cuitlahuac: Santa María de la Magdalena Michcalco ${ }^{7}$, sobre la que hablaré más adelante.

\footnotetext{
3 AGN (Tierras, vol. 1631 exp. 1, cuad. 11, fols. 90r-91v; Congregaciones, vol. 1, exp. 53, fols. 36v-37r). Las congregaciones se llevaron a cabo en dos momentos distintos: entre 1550 y 1564, durante el mandato de don Luis de Velasco, y entre 1595 y 1605, en tiempos del virrey don Gaspar de Zúñiga, que fue virrey hasta 1603 ( $c f$. Gerhard 1986: 28, Fernández Christlieb y Urquijo Torres 2006: 148-149). Por un error heredado, estos últimos autores señalan que el segundo programa de congregación fue hasta 1625. La congregación de Cuitlahuac responde, por tanto, a la del segundo momento.

4 AGN, Congregaciones, vol. 1, exp. 53, fol. 36v.

5 AGN, Congregaciones, vol. 1, exp. 53, fol. 36v.

6 AGN, Congregaciones, vol. 1, exp. 53, fol. 36v.

7 AGN, Tierras, vol. 1681, exp. 6, $1^{\text {a }}$ parte fol. 66v, 70r, 79r.
} 
En cuanto a la cabecera, ya hemos visto que se trataba de un pequeño islote dividido en cuatro barrios. Lo demás era agua, como en 1662 dijo el oidor Antonio de Lara Mogrebejo al subir al campanario de la iglesia ${ }^{8}$. Esta ubicación explica que en 1587, cuando las autoridades españolas impusieron que cada tributario hiciera entrega a la comunidad de cierta cantidad de maíz, los habitantes de Cuitlahuac se quejaran, alegando que no podían cumplir como se les exigía, por no tener tierras de temporal ni regadíos, por estar en medio de la laguna, argumentando que lo que tenían eran unos camellones o chinampas, los cuales usaban para su propio sustento ${ }^{9}$. A mediados del siglo XVIII, parece que el panorama no había cambiado demasiado, motivo por el cual, las autoridades de Cuitlahuac, asfixiadas por lo limitado de su entorno frente a unos pueblos sujetos con cada vez mayor poder económico, comenzaron a buscar la forma de obtener un espacio en tierra firme. Acudieron entonces a los miembros de la Audiencia, a los que explicaron que, por su carácter insular, sufrían de frecuentes inundaciones, con el agravante de que no contaban con el espacio necesario para sembrar o tener ganado, motivo por el cual muchas familias se habían visto obligadas a abandonar sus casas ${ }^{10}$.

En 1752, y tras revisar el caso, el oidor de la Audiencia, Joseph Francisco del Toro, reconoció que el cultivo no era lo propio de sus habitantes, al estar Cuitlahuac internada en la laguna, observando por ello que sus pobladores "no han tenido tanta inclinaz[io]n al cultibo de las tierras, q[uan] to a la utilidad que les produce la pesca, siendo como son dueños de una gran parte de la laguna, la que desfrutan por si o por sus arrendatarios"11. Por tanto, será en esta actividad pesquera en la que me centraré en este trabajo. También en la renta del zacate, pues como antes se ha dicho, Cuitlahuac logró sobrevivir a las agresiones mediambientales de su entorno gracias a los ejidos que se crearon en el lecho de su antiguo lago, destinados al cultivo del zacate.

\section{ENTRE EL AGUA ANDA EL ZACATE. EL MAPA DE LA MAGDALENA MICHCALCO}

El mapa de la Magdalena Michcalco se pintó en 1579, ante la solicitud de una merced de tierras en una zona imprecisa de camellones o chinampas (Fig. 5). Las chinampas son islotes artificiales, generalmente alargados y cercados por cañas ancladas al lecho del lago, entre los que circula el agua y sobre los cuales se cultivaba ${ }^{12}$. En el caso de la cuenca de México, la mayoría de las chinampas se localizaban en los lagos meridionales, donde estaban los manantia-

8 AGN, Tierras, vol. 1780, exp. 7, fol. 395r.

9 AGN, Indiferente virreinal, caja 932, exp. 23, fols. 1r-1v.

10 AGN, Tierras, vol. 1631 exp. 1, cuad. 8, fols. 16v, 30r. Se llega a decir que el agua se metía hasta el claustro del convento. Es probable que los motivos se debieran al cierre de la compuerta de Mexicaltzingo, que impedía que los lagos del sur que estaban a mayor altura inundaran la Ciudad de México, como sucedió en 1816 cuando se reportó que el sur de la cuenca llevaba sufriendo cuatro años de inundaciones por este motivo ( $c f$. Rojas Rabiela 1993a: 309).

11 AGN, Tierras, vol. 1631, exp. 1, cuad. 8, fol. 61r.

12 Sobre este sistema de cultivo $c f$., entre otros trabajos, el de Serra Puche y Castillo Mangas (1992), Rojas Rabiela (1995: 305-312), Losada et al. (2017: 23), o los trabajos de varios autores compilados por González (1992) y Rojas Rabiela (1993b, 1995), entre otros muchos. 
les de agua dulce (cf. Santamaría 1993: 46). Dichos lagos sufrían pocas variaciones en las distintas épocas del año debido a su permanente surtido de agua y a su constante drenaje hacia las partes más bajas, evitando la concentración de sedimentos ( $c f$. Rojas Rabiela 1985: 18) ${ }^{13}$. En el caso del mapa de la Magdalena Michcalco, fue un tal Bernardino Arias, vecino de Cuitlahuac, el que solicitó unas tierras en un área repleta de chinampas, circundada por un río o corriente de agua donde había otros islotes (Fig. 5). En cada uno de ellos aparece una edificación con un glifo toponímico y la lectura del mismo mediante una glosa. Gracias a ello podemos saber que, además de la Magdalena Michcalco, como generalmente se denominaba a este lugar, las otras estancias eran las de Tepetlapan, Tequixquipan y Santo Domingo ${ }^{14}$. A Michcalco lo identificamos por el glifo de un pescado (mich-in) sobre una casa (cal-li); a Tepetlapan por la piedra ( $t e-t l$ y una bandera (pan-tli); a Tequixquipan por los puntos que hay sobre la casa, los cuales hacen alusión al tequesquite (tequixqui-tl) o carbonato de sosa; y a Santo Domingo, por un convento con su atrio y campanario con cruz, pero sobre todo por la cruz dominica que está a su entrada. El objetivo de Bernardino Arias Dávila era introducir en esas tierras sus ovejas, caballos y cabras.

Como era habitual en estos casos, antes de cualquier adjudicación se informaba a la población local sobre el lugar donde se solicitaba la merced con el fin de conocer si podía perjudicar a la comunidad o a algún vecino en particular. Después, se establecía un día para ir a verlo con las autoridades locales, los posibles afectados y todo aquel interesado (lo que se conoce como vista de ojos), momento en el que se realizaba una pintura para valorar las consecuencias de la posible merced ${ }^{15}$. El mapa que aquí se analiza es resultado de ese procedimiento.

Lo primero que en él destaca es una acequia pintada de color azul, la cual circunda las chinampas donde estaban las cuatro estancias y las tierras solicitadas. Alguien añadió tiempo después un camino pobremente dibujado, con una glosa, para dar a entender que el área representada estaba entre Cuitlahuac y Mizquic. Esta dice: "camino de mesquiq[ui] a quytlauaq". Es lo único que nos permite inferir que esa porción de terrenos estaría muy cerca de ambas localidades, aunque como luego veremos, la ubicación de ambos puntos no es del todo precisa. Respecto a la acequia, otra glosa señala: "esta es una çequia q[ue] se pasa para yr a la p[ar]te donde pide bernaldino arias". Es lo que explica que todos tuvieran que llegar en barca hasta la estancia solicitada ${ }^{16}$, que es la que aparece circundada por una línea de color rojo, ubicada entre la Magdalena Michcalco y Tepetlapan, en la cual había dos islotes y varias chinampas. Sus medidas son las que se anotaron a través del sistema de cuenta prehispánico. O sea, una serie de puntos (con valor de 1 cada uno) y banderas (equivalente al numeral 20 cada una), además del brazo para señalar la unidad de medida, es decir, la braza. Esto quiere decir que se trataba de un terreno de 126 x 185 x 130 brazas $^{17}$.

13 En la Relación Universal de 1637 ya se señalaba el peligro al que se exponía la Ciudad de México $(1,907 \mathrm{~m})$ en época de lluvias, al estar los lagos de Xochimilco $(3,119)$ y Chalco $(3,082)$ mucho más altos (en Musset 1992: 59).

14 Para Lockhart (1999: 82, nota ${ }^{\star}$ ), la "estancia" era una "superficie de tierra de propiedad privada para fines agrarios", mientras que "paraje" es el término que usaban los españoles para referirse a "superficies considerables de tierra (probablemente definidas por características naturales)", alejadas de la cabecera (217).

15 AGN, Tierras, vol. 1681, exp. 6, $1^{\text {a }}$ parte fol. $64 \mathrm{r}$.

16 AGN, Tierras, vol. 1681, exp. 6, $1^{\text {a }}$ parte fol. 65r

17 Sobre cuestiones de medidas, $c f$. el excelente trabajo de Valencia (2018). 


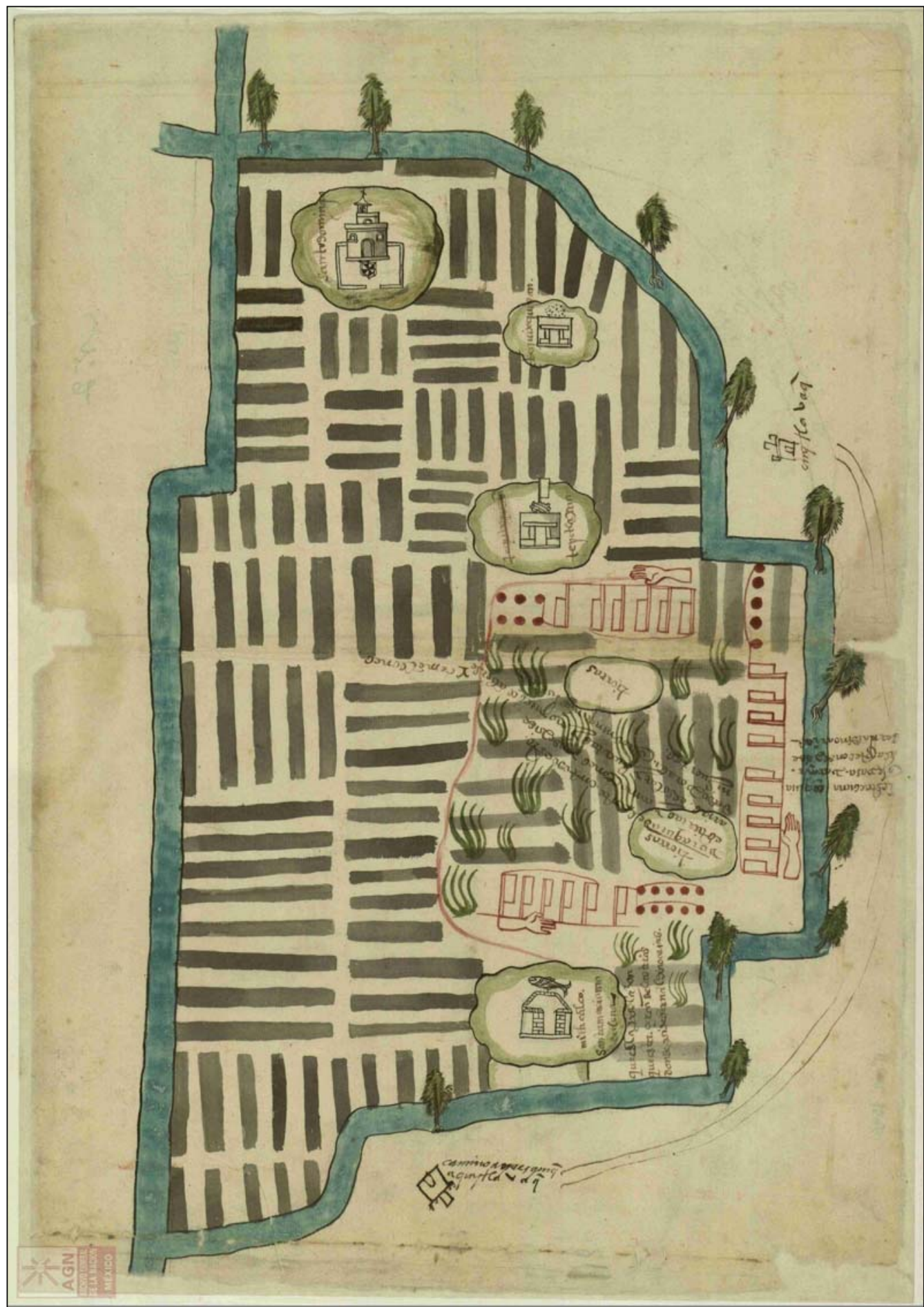

Fig. 5 Mapa de la Santa Magdalena Michcalco. AGN, Tierras, vol. 2681, exp. 6, fol. 2r (Mapoteca núm. 1596). 
Una vez allí, y a la hora de tomar declaración, los testigos de Bernardino Arias dijeron que se trataba de un área de mucha tierra y camellones, aunque baldíos, que nunca habían sido sembrados ni cultivados, por lo que concluían que la merced no hacía daño a nadie ${ }^{18}$. La parte contraria, o sea, las autoridades de Cuitlahuac y un vecino de Mizquic los contradijeron. Respondieron que en aquellos camellones siempre había habido sembradíos de maíz, chile y otras semillas que servían para su sustento, aunque era verdad que estos llevaban cuatro años sin cultivarse debido a la epidemia de cocoliztli que acabó con los macehuales que acarreaban los céspedes y lodos para hacer las chinampas que luego trabajaban ${ }^{19}$.

Contrariado, Bernardino Arias alegó que esas tierras no se sembraban desde antes de llegar los españoles, acusando a los testigos de las autoridades de Cuitlahuac de haber sido comprados con varias dádivas ${ }^{20}$, motivo por el que presentó cinco testigos más a la causa: tres españoles, un mestizo y un indígena, vecinos de Xochimilco y Mizquic. La mayoría señaló tener caballos que llevaban allí a pastar, por ser tierras metidas en la laguna donde los animales estaban libres pero guardados a la vez, sin hacer daño a las sementeras, ya que allí solo se daba agua y zacate para alimentar a las bestias ${ }^{21}$. Pero todo fue inútil. Tras haber paseado por las tierras, el alcalde mayor reconoció que se trataba de una zona de chinampas en el agua donde los indios solían sembrar, y aunque en ese momento los camellones no estaban cultivados, sabía que de otorgarse la merced estos acabarían perjudicados. Un motivo por el que, según él, en aquella parte no se había mercedado antes tierra alguna ${ }^{22}$.

Para terminar solo me queda señalar que, aunque para los españoles la Magdalena Michcalco era una estancia sujeta a Cuitlahuac, las autoridades de este lugar precisaron que no lo estaba al conjunto de la cabecera sino al barrio de Tiçic (cf. Fig. 2). Por ende, debían ser las chinampas que los miembros de la casa o del linaje de este barrio tenían para alimentarse, por lo que de otorgarse la merced quedaban en situación vulnerable.

A continuación veremos cómo se pudo localizar la Magdalena Michcalco y las demás estancias representadas en el mapa de 1579 , de las que ya no queda rastro. Conoceremos, asímismo, en qué se transformó esa área de chinampas y a qué se dedicó su tierra a lo largo del tiempo.

\section{EN BUSCA DE LA MAGDALENA MICHCALCO}

Según el mapa de 1579, el área representada estaba cerca de una vereda que iba de Mizquic a Cuitlahuac, como corroboró el propio alcalde mayor $^{23}$, aunque para hacer la vista

\footnotetext{
18 AGN, Tierras, vol. 1681, exp. 6, $1^{\text {a }}$ parte fols. $66 \mathrm{v}-67 \mathrm{v}$.

19 AGN, Tierras, vol. 1681, exp. 6, $1^{\text {a }}$ parte fols. 68r, 69r, 70r-70v. Se referían a la mortífera epidemia de 1576 que reportan varios documentos. Referencias sobre la misma en García Acosta et al. (2003, II: 118-122).

20 AGN, Tierras, vol. 1681, exp. 6, $1^{\text {a }}$ parte fol. 73r.

21 AGN, Tierras, vol. 1681, exp. 6, $1^{\text {a }}$ parte fols. 76v-78r.

22 AGN, Tierras, vol. 1681, exp. 6, $1^{\text {a }}$ parte fols. fol. 79r.

23 AGN, Tierras, vol. 1681, exp. 6, $1^{\text {a }}$ parte fol. 79r.
} 


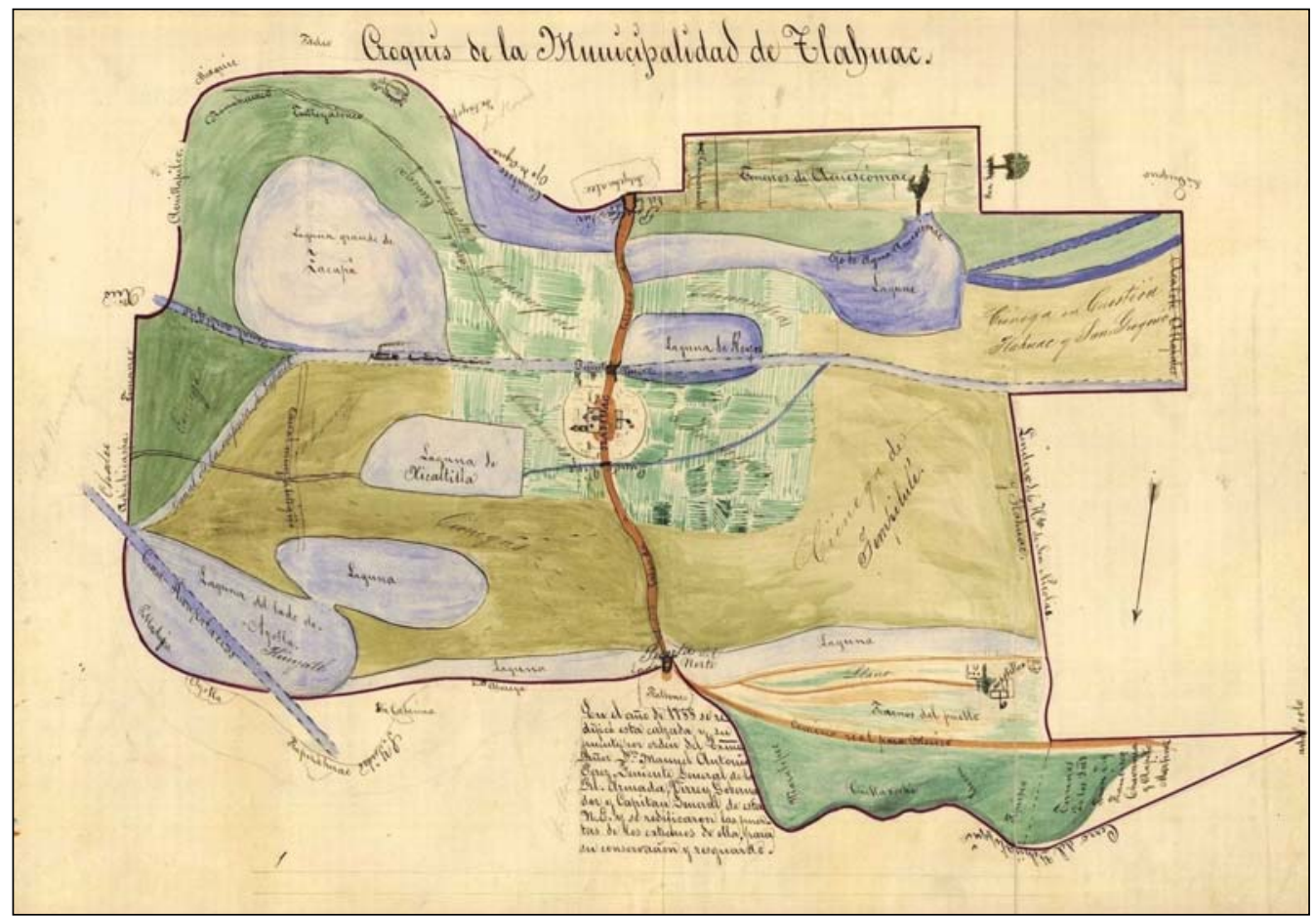

Fig. 6 Croquis de la Municipalidad de Tlahuac. Mapoteca Orozco y Berra, Colección Orozco y Berra, varilla 9, D.F.

de ojos todos los interesados llegaron hasta allí en barca ${ }^{24}$. Lo anterior, y el hecho de que la Magdalena Michcalco estuviera vinculada con el barrio de Tiçic es por lo que se pensaría que el área representada estaba al sur de Cuitlahuac. Lo corroboraría también el hecho de que la mayoría de los testigos que se presentaron en la causa, ya fueran indígenas o españoles, procedieran de Mizquic o Xochimilco, pueblos con los que las tierras en pleito colindaban. Así lo aseguró, por ejemplo, Martín Cano, del barrio de Tlailotlacan (en Mizquic), al decir que estas lindaban con otras de su pueblo ${ }^{25}$, o un tal Damián, del barrio de Tecpan (en Xochimilco), al señalar que dichas tierras estaban en las lindes de donde él era natura ${ }^{26}$. Ahora bien, debido a que Tulyehualco, que es el pueblo que está en el extremo meridional de la calzada que une Cuitlahuac con tierra firme, no está representado en el mapa, es por lo que deduje que los pueblos pintados debían estar hacia el oriente de esta localidad, en dirección a Mizquic. Un asunto que corroboró un plano

24 Debido a que Mizquic y Cuitlahuac estaban asentados en dos islotes en el antiguo lago de Chalco ( $c f$. Figs. 1 y 4), hay dos posibilidades con ese camino de trazo pobre que se añadió en algún momento al mapa: a) su intención era marcar una vía de agua que salía de Cuitlahuac y llegaba por el interior del lago hasta Mizquic; b) el objetivo era ubicar espacialmente las tierras señaladas y marcar el camino que conectaba Cuitlahuac con tierra firme y, de ahí, bordeando la orilla del lago por el sur, hasta llegar a Mizquic. En este último caso, Cuitlahuac debería estar donde se pintó Mizquic y viceversa.

25 AGN, Tierras, vol. 1681, exp. 6, $1^{\text {a }}$ parte fol. 68 r.

26 AGN, Tierras, vol. 1681, exp. 6, 1ª parte fol. 70r. 
de la Mapoteca Orozco y Berra de 1788, donde hallé que por esos rumbos había un lugar glosado como "Santo Domingo" (Figs. 6 y 7), que no podía ser otro que aquel representado en el mapa de 1579 a través de un convento dominico con su atrio.

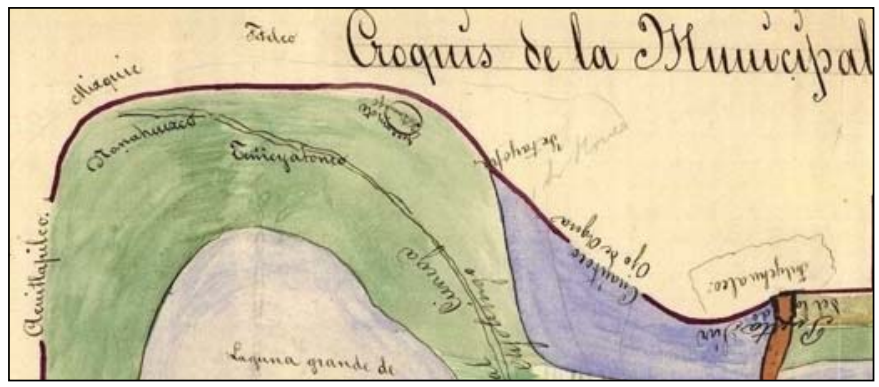

Fig. 7 Detalle del croquis

de la Municipalidad de Tláhuac. Mapoteca Orozco y Berra, Colección Orozco y Berra, varilla 9, D.F.

En ese mapa de 1788 se puede ver, también, que cerca de Santo Domingo hay una glosa que dice Ixtayopan, hoy San Juan Ixtayopan, lugar que en un mapa actual se puede ubicar cerca de San Antonio Tecomic. Aunque Tecomic no aparece en ninguno de los mapas consultados, no es casual que dos de los testigos de Bernardino Arias fueran de allí, pues como ellos señalaron, sus tierras estaban pegadas a la que él deseaba. Es lo que por ejemplo dijo Pedro de Castañeda, principal de San Antonio Tecomic, sujeto a Xochimilco, al indicar que sus tierras patrimoniales estaban junto a las que pedía Bernardino Arias, muy próximas, a su vez, a la estancia de la Magdalena [Michcalco] ${ }^{27}$. Esto quiere decir que el área representada en ese mapa del AGN era pequeña, y lo mismo sus estancias. Y aunque todas desaparecieron, es sorprendente saber que aún hay memoria de las mismas.

Como antes se ha dicho, San Juan Ixtayopan todavía existe. En una entrevista que la periodista Karina Vázquez (2016, en línea) le hizo al ejidatario de la zona, el Sr. Gustavo Vázquez Rojas, este explicó que el ejido de Ixtayopan consistía de una reserva de 60 mil hectáreas de cultivo divididas en parcelas de aproximadamente una hectárea cuadrada cada una ${ }^{28}$. Toda el área estaba además comunicada por caminos, llamados "carriles", probablemente antiguos canales, pues a decir del señor Vázquez Rojas, aquella fue una zona de manantiales que por "rascar los pozos" se fue secando. Pero lo más interesante de su declaración fue cuando señaló que cada parcela recibía un nombre "como El Cuarto, Tercero, Segundo, Santo Domingo y La Magdalena”. La coincidencia de ambos nombres, uno tras otro, además de su ubicación, no hace más que confirmar que allí estuvieron alguna vez ambas estancias, junto con la de Tepetlapan y Tequixquipan. Sin embargo, no hablamos aquí de pueblos sino de ciertos "terremotes" convertidos en estancias, rodeados de chinampas de cultivo donde quizá podía haber algunos jacales.

La transformación de este entorno, como sucedió en otras partes del Altiplano Central, fue progresiva y el uso de su espacio acorde a dicha transformación. Así, pues, si las chinampas dejaron de cultivarse en el siglo XVI, tenemos noticias de que en el siglo XVIII, concretamente en 1762, la estancia de Santo Domingo acabó convertida en una ciénaga que

27 AGN, Tierras, vol. 1681, exp. 6, $1^{\text {a }}$ parte fol. 71r.

28 Es posible que se trate de un error y se refiriera a 60 hectáreas. 
sus autoridades rentaban a los abastecedores de carne de la Ciudad de México para que allí pastara su ganado, principalmente de vacas, y con cuyos beneficios pagaban el tributo real ${ }^{29}$. Fue entonces un área codiciada y el origen de un pleito de largos años con las autoridades de Mizquic, que en cierto momento trataron de hacer creer que la ciénaga era suya ${ }^{30}$. En las averiguaciones que se hicieron en torno al caso, los testigos de Cuitlahuac, entre ellos su gobernador, siempre argumentaron que la ciénaga de Santo Domingo les pertenecía desde tiempo inmemorial, además de ofrecer otros datos de interés:

Que de immemorial tiempo al precente tubieron nuestros ante pasados Padres, y Abuelos y tenemos nostros por propria [sic] nuestra una Cienaga nombrada S[an]to Domingo, la qual acaba por el lado Del oriente en el paraje llamado Ystepan en un Terromote alto, que sirve de Lindero que diuide nuestras Tierras de las del Pueblo de Misquique [...] por cuyos Pastos ha pagado el obligado abastesedor de Carnes de la corte de Mex[i]co a mi Pueblo Ochenta p[eso]s cada un año [...] (la cursiva es mía). ${ }^{31}$

Del texto se concluye que Santo Domingo, en la ciénaga del mismo nombre, es el lugar que podemos apreciar en el mapa de 1788 (Fig. 7), glosado como "Gerromote [sic] S[an] to Domingo". Los terremotes, como Serra señaló, eran islas artificiales construidas a partir de un encofrado de madera hecho de troncos y estacas, que se rellenaba con capas alternas de lodo y tules, y terminaba en forma de montículo, con una base estable para albergar unidades de habitación (1995: 48, 50). Se trata del sistema constructivo que en las lagunas del río Lerma se conoce como "altado", en el que también se alternaban planchas de yerbas acuáticas con otras de lodo para ganarles tierras al lago con fines habitacionales (Albores 2002: 60). Lo anterior permite sostener que Michcalco, Tepetlapan y Tequixquipan, las otras estancias representadas en el mapa de 1579, también eran terremotes, junto a los que había varias chinampas ${ }^{32}$.

\section{LA PESCA EN LA LAGUNA DE CUITLAHUAC}

Como ya hemos visto, Cuitlahuac eran un pueblo eminentemente pesquero. Por tanto, no es de extrañar que el dios de la caza lacustre -Iztacmixcoatl- internara a su gente en los lagos del sur de la cuenca, indicándoles el lugar donde debían fundar su ciu-

\footnotetext{
29 Algo similar sucedió en la laguna de Lerma. Albores señala que su pasto propició el uso de la "ganadería lacustre", que fue la que impulsó las unidades ganaderas durante la Colonia (2002: 65).

30 Toda esta disputa se halla en AGN, Tierras, vol. 1597, exp. 2. La ciénaga de Nanacahuisco o Nanacacahuixco era la de Mixquic y se empleó para los mismos fines (cf. Fig. 6).

31 AGN, Tierras, vol. 1597, exp. 2, fols. 29r-30v.

32 Rojas Rabiela señala que con el nombre de terremotes se conoce también a una serie de chinampas elaboradas a partir de un cimiento poco profundo en el interior del lago, cuyo perímetro se delimitaba con carrizos y estacas largas, el cual se iba rellenando con capas alternas de tierra y césped (1993a: 310-311). Aunque Serra señaló que el sistema constructivo de terremotes y este tipo de chinampas era ligeramente diferente (1995: 50), me parecen tan similares que es necesario investigar más en esta dirección.
} 
dad (Anales de Cuauhtitlan 1992, párr. 84). La vara de esta deidad, a la que ellos también adoraban, tenía el nombre de Amimitl, y aunque su nombre se traduce como "flecha de agua", es probable que aludiera a la fisga, pues con ella es con la que se atrapaban peces, patos y ranas ${ }^{33}$. Otro dios afín a estos ambientes era Opochtli, cuyos atributos eran la red de mango, la fisga, el remo y quizás el mazo ${ }^{34}$. Sin embargo, de ninguno hay rastro en la documentación colonial, aunque es interesante saber que, en Xochimilco, hasta hace muy poco, aún se celebraba la fiesta del pescado (Pérez Espinosa 1985: 102).

Difícil es saber cómo era el reparto de las aguas de los lagos antes de la llegada de los españoles, y si tal reparto existía. Lo que sabemos es que, acabada la Conquista, la distribución de las tierras y las aguas a ellas aparejadas estaba a cargo de los conquistadores, al menos hasta 1534, cuando estas se convirtieron en bienes realengos, siendo los virreyes, con el parecer de los cabildos, los autorizados para su reparto (Dougnac Rodríguez 1994: 404, 418). Los lagos de Chalco y Xochimilco formaron, consecuentemente, parte de esta política y, por ende, ni los pueblos ni los particulares podían pescar en ellos sin su consentimiento ${ }^{35}$. Y aunque lo frecuente es que la Audiencia cediera sus aguas a los pueblos, esta siempre estuvo al frente de cualquier regulación y transacción emprendida por los cabildos indios:

porque Conforme a sus disposiciones en ambos derechos Ciuil y Real los Rios y Lagunas como la Referida perteneçen Comunmente a todos los Vecinos moradores de las Cuidades [sic] Villas y Pueblos para que libremente puedan Vssar y aprovecharse de ella en la Pesca y demas Ministerios [...] que no solo a aquellos que Moran y Viven en aquella tierra donde estan los Rios y Lagunas les es permitido Su aprovechamiento, Sino tambien a los que son de tierras estrañas. ${ }^{36}$

Es lo que corroboran algunos documentos de mediados del siglo XVII, donde vemos cómo las autoridades de Cuitlahuac, con aprobación de la Audiencia, estuvieron rentando su legua de laguna a varios particulares con la condición de que no se les impidiese a ellos la pesca ${ }^{37}$. No obstante, no todos los arrendatarios cumplían puntualmente con sus contratos, de ahí que ocasionaran grandes daños a los pescadores que vivían de sus productos, ya fuera para su consumo, la venta o el pago del tributo ${ }^{38}$. Por lo anterior, es frecuente que

\footnotetext{
33 Sobre Iztacmixcoatl y Amimitl, $c f$. Castañeda de la Paz (2018: 61-74).

34 Así aparece en el Códice Florentino (1979, lib. 1, apéndice, fol. 39r) frente a un grupo de pescadores. Cf. también los Primeros Memoriales (fol. 263r). Es Brockmann quien sugiere que es un mazo o hasta una macana (2004: 27-28). Para las redes de mango consúltese este último autor (24-25).

35 AGN, Mercedes vol. 63, fol. 6v.

36 AGN, Tierras, vol. 1780, exp. 7, fol. 424v.

37 AGN, indios vol. 32 , exp. 322, fol. 287v.

38 En 1651, las autoridades de Cuitlahuac señalaban que le habían rentado su parte de laguna a varios españoles a los que tuvieron que denunciar para que cesaran sus actividades por fin de contrato y porque les debían un dinero (AGN, indios, vol. 16, exp, 66, fols. 64v-65r). En 1691 se celebró un contrato de cuatro años con un tal Joseph Gutiérrez de Villavicencio, el cual se volvió a renovar en 1695 por cuatro años más (AGN, indios, vol. 32, exp. 322, fols. 287v-288r). Sobre estos daños, $c f$. también AGN, Indios, vol. 17, exp. 49, fol. 74r; Indiferente virreinal, exp. 18, caja 6677, fol. 1 r.
} 
todavía a finales del siglo XVII se siguiera pregonando las cuantiosas multas que debían pagar los que incurrían en algunos delitos, siendo necesario recordarles que la laguna formaba parte de los bienes realengos y no de los indios ni de otros particulares ${ }^{39}$.

Gracias a un mapa del siglo XVIII sabemos que las aguas que circundaban Cuitlahuac tenían su propia nomenclatura, aunque por falta de información no tengo la certeza de que lo mismo sucediera en el pasado. Según este mapa, la parte oriental del lago se conocía como laguna de Zacapa; la del sur como Quautotliapan o Tuliagualco (Tulyehualco); y la situada al poniente como laguna de los Reyes, la cual se extendía en dirección hacia Santa Catarina, la Venta Nueva y Tlapacoya, donde en cierto documento se dice que las aguas eran muy malas por ser laguna rasa y suelo tequesquitoso ( $c f$. Fig. 6). Un motivo por el cual, mientras en la laguna de Tulyehualco y en la de los Reyes se criaba el pescado más grande y de mejor calidad, por ser sus aguas muy dulces, en la del norte no se criaba ninguno ${ }^{40}$. Lo cierto es que como los análisis de Humboldt corroboraron, mientras las aguas del lago de Texcoco eran las peores por estar llenas de muriato y carbonato de sodio, hidrógeno sulfuroso y acetato de plomo, componente que también llegó a encontrar en el lago de Chalco (en Musset 1992: 62), las del lago de Xochimilco -como una comisión del gobierno determinó en 1853- eran las más puras y limpias, a pesar de su mal sabor por los juncos y hierbas de su orilla (62).

En los lagos abundaba el pescado blanco, las ranas, los ajolotes, el "pexe Reyes", las almejas y los juiles, que hasta hace poco todavía se consumían (Pérez Espinosa 1985: 107) ${ }^{41}$. El pescado se envolvía en hojas de atlacueçonan, o sea, en nenúfares de la laguna ("tla-

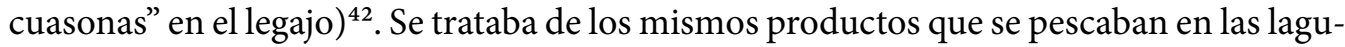
nas del río Lerma, debido a que, como Musset bien explicaba, las aguas de ambos lados estuvieron alguna vez en contacto (1992: 61) ${ }^{43}$.

De los códices se infiere que los utensilios para la pesca eran las fisgas de diferentes puntas para cazar peces y patos, además de las redes de mango, los remos o los mazos como vimos que portaban los dioses de los pueblos lacustres ${ }^{44}$. En el siglo XVII todavía se seguían empleando las redes y las fisgas, aunque estas dejarían de ser de carrizo para pasar a ser confeccionadas de metal. Los chinchorros fueron introducidos en la Colonia (Rojas

\footnotetext{
39 AGN, indios, vol. 30, exp. 460, fol. 440r. La real Audiencia también se encargó de reglamentar todo lo concerniente a la limpieza o reparación de acequias, albarradones, caños, etc. (cf. Dougnac Rodríguez 1994: 419).

40 AGN, Tierras, vol. 1780, exp. 7, fols. 395r-396r. No es fortuito, por ello, que formaran parte de los bienes realengos y no se cedieran a los pueblos (fols. 396r-396v).

41 Sobre la riqueza de la fauna del lago en tiempos prehispánicos, $c f$. Niedeberg (en Rojas Rabiela 1985: 18-21). Rojas Rabiela hace un buen resumen de las especies a partir de las crónicas coloniales (1985: 21-31). Interesantes son los datos de Pérez Espinosa (1985: 105-114) para el periodo más reciente (siglo XX), donde también se habla del consumo de ranas verdes y negras, almejas, etc. (111-112). Para el pez rey y las almejas, $c f$. AGN, Indios, vol. 4, exp. 942, fol. 252r.

${ }^{42}$ AGN, Tierras, vol. 1780, exp. 7, fol. 360r.

43 El autor se refiere al momento en el que las montañas del eje neovolcánico aislaron los lagos de la cuenca de México y provocaron que estos no pudieran volver a desaguar en el río Lerma.

44 Con la fisga de punta de arpón se capturaban los peces; con la de doble punta (minacachalli), los patos (cf. Cervera Obregón 2007: 134, 2008: 211).
} 
Rabiela 1985: 38), sin ser claro si los anzuelos y cucharas también ${ }^{45}$. En el valle de Lerma, donde la antigua laguna quedó convertida en una ciénaga que acabó por desaparecer en la década de 1970, se siguió empleando la red y la honda (cf. Albores 2002: 56, 62), aunque de ella no se ha hallado referencias en este lado de la cuenca.

Los testimonios de algunas personas durante la Colonia señalan que los productos de los lagos de Chalco y Xochimilco se vendían en la plaza pública de la Ciudad de México. María de Espinosa, viuda y natural de Cuitlahuac, precisó que ella se los compraba a los pescadores de Cuitlahuac, Mizquic y Chalco para venderlos los viernes y sábados en dicha plaza, aunque una parte de la ganancia la empleaba para pagar el tributo. Lo anterior, cuando los comerciantes como ella no eran asaltados en el camino para robarles la mercancía ${ }^{46}$.

\section{LITIGIOS, VISTAS DE OJOS Y AMOJONAMIENTOS EN LA LAGUNA DE CUITLAHUAC}

A continuación, nos adentraremos en un caso de estudio que nos permitirá conocer la no siempre apacible vida de los pescadores de los lagos y la realidad de su día a día, a partir de varios legajos que hacen referencia a la vista de ojos que se hizo en el lago de Chalco en 1662, a cargo del oidor de la real Audiencia, don Antonio de Lara Mogrobejo. Dicha vista de ojos salió a relucir en dos ocasiones, poniendo de relieve los problemas de lindes y arrendamiento de aguas. La primera vez fue en 1693, con motivo de los pleitos entre las autoridades de Cuitlahuac y el español Juan de Castañeda porque no se estaban respetando las leguas de laguna que cada uno tenía asignadas ${ }^{47}$. La segunda vez fue en 1704 , con motivo de un nuevo pleito con Juan de Castañeda pero, ahora, por venderle su media legua de laguna a un tal Ramón Espiguel y Ávila ${ }^{48}$, quien llegó a tomar posesión de sus aguas recorriéndolas en canoa, arrancando tules y arrojando agua ${ }^{49}$.

Nos remontamos así a 1662, cuando el oidor de la Audiencia otorgó una legua de laguna a los naturales de Cuitlahuac para que pudieran pescar en su cuadro o circunferencia, y media legua de laguna a Juan de Castañeda "el viejo", español y vecino de Chalco ${ }^{50}$.

45 Estos utensilios aparecen mencionados en AGN, Mercedes, vol. 63, fol. 73r; Tierras, vol. 1780, exp. 7, fols. 395r, 402v, 433r. Sobre el tema consúltese Rojas Rabiela (1985: 37-42). El chinchorro es una gran red que se mantiene a flote en su parte superior, al sujetarse en cada extremo por unas cuerdas con boyas. Unos cabos con plomos son los que la mantienen en el fondo ( $c f$. Montañez Rivera 2013, en línea). Las cucharas son señuelos de metal, ideales para aguas poco profundas. Cuando se mueven parecen peces pequeños que engañan al pescado (Gutiérrez 2017, en línea).

46 AGN, General de Parte, vol. 2, exp. 1042, fol. 234r; exp 600, fol. 138r. Sobre los asaltantes, se dice que eran españoles, mestizos y mulatos (AGN, General de Parte, vol. 2, exp. 1042, fol. 234r).

47 Información más breve sobre estas disputas se hallan en AGN, Indios, vol. 30, exp. 459; vol. 32, exp. 156 y exp. 322; Mercedes, vol. 63). El texto más extenso está en AGN, Tierras, vol. 1780, exp. 7.

48 AGN, Tierras, vol. 1780, exp. 7, fol. 360v. Tenemos registros de muchas de vistas de ojos en tierra firme, pero raras son las realizadas en los lagos.

49 AGN, Tierras, vol. 1780, exp. 7, fol. 351r. Como en toda vista de ojos, en esta ocasión se dice que también se pintó un mapa, pero no hay rastro del mismo.

50 AGN, Indios, vol. 30, exp. 459, fols. 439r-439v. 
Para evitar que ninguno se metiese en las aguas del otro, se pusieron una serie de estacas a modo de mojoneras por toda la media legua ${ }^{51}$, aunque los problemas surgieron cuando, tras la muerte de Juan de Castañeda "el viejo" en 1693, las autoridades de Cuitlahuac denunciaron que su hijo, junto con personas carentes de títulos y derechos, se estaba introduciendo con sus redes de pescar en su legua de laguna, sin pago de arrendamiento alguno. Una situación que aprovecharon para solicitar a la Audiencia un contrato de arrendamiento, en esta ocasión por nueve años y a 100 pesos por persona. Para lograrlo, es posible que por ello dijeran que con ese ingreso contribuirían al ornato de su iglesia ${ }^{52}$.

En noviembre de ese año se procedió entonces a renovar las mojoneras que el oidor Lara Mogrobejo había puesto en 1662, para lo cual se solicitó que estuvieran presentes cada una de las partes: Juan de Castañeda (hijo), las autoridades de Cuitlahuac y varios de los arrendatarios que estos tenían en su media legua de laguna. Todos se embarcaron en canoas de distinto tamaño y fueron navegando hasta llegar a unos tulares en la ribera del cerro de Xico, donde también estaba la acequia real que iba de Chalco a la Ciudad de México ( $c f$. Figs. 3 y 6$)^{53}$. A partir de ese punto comenzaron a medir hacia el norte, poniendo estacas a modo de mojoneras, hasta dar con unos "zacatones y ciénagas" donde tuvieron que parar la medida por no haber más laguna ${ }^{54}$. Entonces se informó que ni las autoridades de Cuitlahuac podían pescar en esa media legua ni los españoles en la de los otros ${ }^{55}$. Lógicamente, los naturales de Cuitlahuac mostraron su inconformidad argumentando que la medida no procedía porque la media legua en la que Juan de Castañeda (padre) pescaba estaba dentro de la legua de laguna de ellos, como decía el antiguo memorial que sacaron a relucir, en el que el oidor sostenía lo siguiente:

Y los españoles q[u]e tuuiesen licenzia del Gou[ernad]or en toda la legua; como no entren a pescar en ning[u]na parte de las comprendidas en d[ic] ha legua; excepto Juan de castañeda que ha de poder pescar en la media legua, en conforme de los determinado por esta real audiencia. ${ }^{56}$

Por tanto, todo apunta a que, en 1693, Juan de Castañeda (hijo) estaba tratando de hacer creer que la real Audiencia le estaba otorgando derechos de propiedad sobre la media legua de laguna, con los cuales podía decidir quién pescaba en ella. La preocupación

\footnotetext{
51 AGN, Indios vol. 30, exp. 459, fol. 440r; Indios, vol. 32, exp. 156, fol. 151r.

52 AGN, Indios vol. 30, exp. 439, fol. 339v.

53 Ese paraje debió estar a la altura del barco de vapor que surca las aguas de esa acequia, junto al cerro de Xico (cf. Fig. 6).

54 AGN, Mercedes, vol. 63, fols. 71r-72r. Interesante resultan los detalles de los instrumentos con los que se hizo la medida (fol. 71r).

55 Debido a que el comunicado se hizo desde Ayutla, se infiere que la media legua de laguna de Juan de Castañeda era la que iba desde el cerro de Xico hasta el pueblo de este nombre (AGN, Mercedes, vol. 63, fol. 72r). Un pleito de 1777 con los descendientes de Juan de Castañeda lo corrobora. En él se presentan como testigos algunos pescadores del cerro de Xico que faenaban en esa parte de laguna, a la que conocían como laguna de Ayutla (AGN, Tierras, vol. 1908, exp. 8, fols. 6r, 7v-8v).

56 AGN, Mercedes, vol. 63, fol. 73r.
} 
de las autoridades de Cuitlahuac no era para menos, pues, de lograrlo, los peces solo bajarían a su mitad por estar la de ellos repleta de zacatones y tulares ${ }^{57}$.

El representante de Juan de Castañeda salió al frente negando los argumentos de Cuitlahuac y señaló que el día de la vista de ojos ellos asistieron y consintieron los antiguos linderos, sin ser su culpa el estado en el que se encontraba la laguna ${ }^{58}$. Y si los naturales habían argumentado que si se les permitía rentar la laguna dedicarían parte del dinero al ornato de la iglesia, Juan de Castañeda propuso, para inclinar la balanza a su favor, multar a todos los que se metieran en sus aguas a faenar y con ese dinero reedificar el palacio real ${ }^{59}$. Todo parece indicar que ganó, pues como al principio de este apartado se dijo, Juan de Castañeda (hijo) logró vender su media legua de laguna a un tal Ramón Espiguel y Ávila en 1704. Un percance que obligó a que se tuviera que volver a medir la parte de laguna que estaba al oriente de Cuitlahuac -la de Zacapa-, aunque en esta ocasión se solicitó que la medición se hiciera desde el cerro de Xico hacia el sur (y no hacia el norte) por la mejor calidad de las aguas y, por ende, la abundancia de peces en ella ${ }^{60}$. Parece que así se hizo, pues desde los tulares a los pies de ese cerro se metieron por medio de la laguna de Tuliagualco (Tulyehualco) y la acequia real que iba desde Ayotzingo a la Ciudad de México ${ }^{61}$.

No obstante, y pasado el tiempo, la real Audiencia reconoció que Juan de Castañeda no estaba autorizado a vender su media legua de laguna. Lo hizo en 1777, cuando dos hermanos conocidos como Manuel y Felipe Cabrera justificaron su derecho a pescar en la media legua de laguna por ser su descendiente ${ }^{62}$. Ante tal tropelía, las autoridades de Cuitlahuac alegaron que el contrato con Juan de Castañeda ya había expirado, motivo por el cual, esa media legua de laguna había vuelto a ser suya ${ }^{63}$. Al final de desató un episodio de violencia que pone de manifiesto las tensiones que se generaban por los derechos del agua.

Según la versión de las autoridades de Cuitlahuac, cuando sus pescadores fueron a faenar en su legua de laguna se encontraron a los Cabrera pescando en ella. Puesto que ya se les había notificado que no podían hacerlo se acercaron para saber de su osadía. Pero fue al pedirles que se retiraran cuando vieron llegar varias canoas con chinos y mulatos armados con garrotes, con quienes se emprendieron a golpes, de tal suerte que algunos huyeron a nado, otros en canoas, mientras que tres de ellos fueron capturados y encerrados en casa de Felipe Cabrera para después ser enviados a la cárcel de Tlalmanalco ${ }^{64}$. También

57 AGN, Mercedes, vol. 63, fol. 73r. Acusaron a Juan de Castañeda de impedirles pescar, quitándoles sus chinchorros, cucharas, redes y fisgas (AGN, Mercedes, vol. 63, fol. 73r; Tierras, vol. 1780, exp. 7, fols. 395r $402 \mathrm{v}, 433 \mathrm{r}$ ).

58 AGN, Mercedes, vol. 63, fols. 71v, 73r, 73v.

59 AGN, Mercedes, vol. 63, fol. 74v.

60 AGN, Mercedes, vol. 63, fols. 397r-397v. No obstante, se señaló que al llegar a la media legua se pusieron estacas para permitir que Juan de Castañeda pescara.

61 Las medidas se hallan en AGN, Tierras, vol. 1780, exp. 7, fols. 398v-401r. Para cuestiones de medidas y equivalencias $c f$. el trabajo de Valencia (2018).

62 AGN, Tierras, vol. 1908, exp. 8, fol. 1r. Las autoridades de Cuitlahuac precisaron que eran vástagos del hijo de Juan de Castañeda y vivían en Ayutla.

63 AGN, Tierras, vol. 1908, exp. 8, fol. 1r.

64 AGN, Tierras, vol. 1908, exp. 8, fol. 1v. 
se les confiscaron tres canoas, redes y utensilios de pesca entre los que se había varios "hierros", como se denominaban a las fisgas de pescar y que hacen suponer que ya eran de metal y no de madera ${ }^{65}$. Ahora bien, según la otra versión, el detonante del tumulto lo provocó el atrevimiento de los pescadores de Cuitlahuac, al quitarles a los Cabrera su chinchorro de pescados, lo que explica que a los otros lo socorrieran chinos y mulatos en canoas con cuchillo en mano ${ }^{66}$. Fuera como fuese, la justicia acabó dando la razón a las autoridades de Cuitlahuac ${ }^{67}$, pero el caso demuestra que, a pesar de la aparente regulación en torno a las aguas, las leyes se prestaban a engaños, afectando negativamente la vida de los pescadores de Cuitlahuac y de los lagos en general.

\section{CONCLUSIONES}

La literatura antropológica sobre algunos pueblos lacustres del sur de la cuenca de México, y también del valle de Lerma, es abundante y valiosa, pero no sucede lo mismo con la producción histórica (etnohistórica), bastante más escasa. Cuitlahuac, por ejemplo, carece de una historia escrita, de ahí el valor de este trabajo, a partir del cual podemos comenzar a tener una visión más amplia acerca de las transformaciones, pero también de las continuidades, a las que se ha visto sometido su paisaje y, consecuentemente, la vida de sus habitantes.

Como se constanta a través de este trabajo, Cuitlahuac fue un pueblo eminentemente pesquero que, a diferencia de los pueblos de la ribera del lago, no contaba con grandes extensiones de tierra para cultivar, montes donde cortar leña o canteras de las que extraer material. Desconocemos cómo era el reparto de las aguas del lago antes de la llegada de los españoles, si es que tal reparto existía. Lo que es un hecho es que a la llegada de estos, sus aguas se convirtieron en bienes realengos sujetos a una serie de disposiciones, de tal forma que los habitantes de Cuitlahuac solo se pudieron beneficiar de la parte oriental de la laguna (en el lago de Chalco), donde estaba la de Ayutla y la de Zacapa. La primera, menos rica por su suelo tequisquitoso; la segunda, con aguas de mejor calidad, pues hasta ella llegaba el pescado que se criaba en los manantiales del sur y del occidente, de aguas mucho más dulces. Los productos del lago debieron ser, por tanto, primordiales en la dieta de su población, aunque con ellos debieron comercializar en la Ciudad de México, no solo para variar esa dieta sino para obtener con qué pagar el tributo real. Contaban también con una serie de chinampas para su sustento en la orilla meridional del lago (en la Magdalena Michcalco), pero la epidemia de cocoliztli de 1576 mermó tanto a la población que fueron abandonadas y el área convertida en un oasis de pastos que comenzaron a rentar a los abastecederos de la Ciudad de México para que sus vacas

\footnotetext{
${ }_{65}$ AGN, Tierras, vol. 1908, exp. 8, fols. 4r-4v, 5r, 6v, 7r, 8r.

6 AGN, Tierras, vol. 1908, exp. 8, fols. 5v, 6v, 8r, 8v.

67 Se liberó a los que estaban en la cárcel, se les devolvieron los bienes embargados y se confiscaron los que tenían los Cabrera en sus casas, quienes para entonces ya habían huido de Ayutla, aunque las autoridades de Cuitlahuac le concedieron el perdón (AGN, Tierras, vol. 1908, exp. 8, fols. 10v-12v).
} 
tuvieran donde pastar. Unas ganancias que en el siglo XVIII, y quizás desde antes, estuvieron destinadas, asimismo, para el obligado tributo real.

Pero como aquí hemos visto, la vida de los habitantes de Cuitlahuac no siempre era tan apacible como pudiera pensarse. Varias quejas a la real Audiencia demuestran que el negocio de la venta de los productos de la laguna en la Ciudad de México era arduo por los asaltos en el camino y los problemas con la obtención de licencias para su venta. Los arrendamientos de algunas leguas de lagunas a los españoles, dentro de la parte asignada a los pescadores de Cuitlahuac, sumió también a sus autoridades en varias disputas por el frecuente incumplimiento de los contratos, obligando a reiteradas vistas de ojos $\mathrm{y}$ al amojonamiento de las aguas. Todo lo anterior en un pueblo donde las fuentes dan a entender que vivía una población multiétnica compuesta de indígenas, españoles, mestizos, y hasta chinos y mulatos.

\section{BIBLIOGRAFÍA}

AGN Archivo General de la Nación. Ramos consultados: Congregaciones, General de Parte, Indiferente virreinal, Indios, Mercedes y Tierras.

Albores, Beatriz (2002) "Ambiente y cultura lacustre en la Historia del Alto Lerma Mexiquense”. En: Martín Sánchez (ed.) Los estudios del agua en la cuenca Lerma-Chapala-Santiago. México, Colegio de Michoacán - Centro Universitario de Ciencias Sociales y Humanidades de Guadalajara: 49-69.

Anales de Cuauhtitlan ver Códice Chimalpopoca.

Brockmann, Andras (2004) La pesca indígena en México. México, IIA-UNAM.

Castañeda de la Paz, María (2018) "La Tira de la Peregrinación". En: Juan Octavio Torija Aguilar (ed.) La literatura mexicana en la época de Cervantes. XXVIII Coloquio Cervantino Internacional. México, Centro de Estudios Cervantinos, A.C.Fundación Cervantina de México, A.C. - Museo Iconográficos del Quijote- Universidad de Guanajuato: 55-84.

Cervera Obregón, Marco Antonio (2007) El armamento entre los mexicas. Madrid, Consejo Superior de Investigaciones Científicas - Instituto Histórico Hoffmeyer Instituto de Historia - Ediciones Polifemo.

---- (2008) Breve historia de los aztecas. México - Madrid, Nowtilus.

Códice Chimalpopoca. Anales de Cuauhtitlan y Leyenda de los Soles (1992) México, IIH-UNAM.

Códice Florentino (1979) 3 vols. México, Archivo General de la Nación.

Dougnac Rodríguez, Antonio (1994)Manual de historia del derecho indiano. México, IIH-UNAM.

Fernández Christlieb, Federico y Urquijo Torres, Pedro Sergio (2006) "Los espacios del pueblo de indios tras el proceso de Congregación, 1550-1625". Investigaciones Geoográficas. 60: 145-158. 
García Acosta, Virginia, Pérez-Zevallos, Juan Manuel y Molina del Villar, América (2003) Desastres agrícolas en México. Catálogo histórico. 3 vols. México, CIESAS - Fondo de Cultura Económica.

Gerhard, Peter (1986) Geografía histórica de la Nueva España, 1519-1821. México, Instituto de Investigaciones Históricas e Instituto de Geografía UNAM.

GonzÁlez, Carlos Javier, comp. (1992) Chinampas prehispánicas. Serie Arqueología. México, Instituto Nacional de Antropología e Historia.

GutiÉRrez, Esteban (2017) “Pesca con cuchara. Mejores tipos”. https://www.lapesca.org/ pesca-con-cucharas/ [26.06.2020].

Jiménez Osornio, Juan José y Gómez-Pompa, Arturo (1993) "Las chinampas mexicanas”. En: Teresa Rojas Rabiela (ed.) La agricultura chinampera. México, Universidad Autónoma de Chapingo: 253-269.

LockHART, James (1999) Los nahuas después de la conquista. Historia social y cultural de los indios del centro de México, siglos XVI-XVIII. Stanford, Stanford University Press.

Losada, Hermenegildo R., Vargas, Juan M., Cortés, José, Vieyra, Jorge E., Alemán, Viridiana, RodríGuez, René y LunA, Lorena (2017) “The Original Villages of Mexico City: New Ways Describe History and Agriculture". Journal of Anthropology and Archaeology. 5 (2): 18-30.

Medina HernándeZ, Andrés (2006) "Las fronteras simbólicas de un «pueblo originario»: una mirada etnográfica a las comunidades de Tláhuac, Distrito Federal”. LiminaR. 4 (1): 77-91.

---- (2007) "Pueblos antiguos, ciudad diversa. Una definición etnográfica de los pueblos originarios de la Ciudad de México”. Anales de Antropología. 41 (II): 9-52.

Montañez Rivera, G. Josué (2013) "Características claves de un arte de pesca. El chinchorro de línea”. http://gulfprogram.ucsd.edu/blog/fisheries/caracteristicas-clavede-un-arte-de-pesca-el-chinchorro-de-linea/ [26.06.2020].

Musset, Alain (1992) "El extraño mundo del agua". En: Alain Musset, Pastora Rodríguez Aviñoá y María Palomar (eds.) El agua en el valle de México. Siglos XVI-XVIII. México, Pórtico de la Ciudad de México - CEMCA: 19-68.

Narchi E., Nemer y Canabal Cristiani, Beatriz (2014) "Subtle Tyranny. Divergent Constructions of Nature and Erosion of Traditional Ecological Knowledge in Xochimilco". Latin American Perspectives. 42 (5): 90-108.

Pérez Espinosa, José Genovevo (1985) "La pesca en el medio lacustre y chinampero de San Luis Tlaxialtemalco". En: La cosecha del agua en la cuenca de México y la pesca en el medio lacustre y chinampero de San Luis Tlaxialtemalco. México, CIESAS.

Primeros MEMoriales ver Sahagún.

Rojas Rabiela, Teresa (1985) La cosecha del agua en la cuenca de México. México, CIESAS.

(1993a) "La tecnología indígena de construcción de chinampas en la cuenca de México". En: La agricultura chinampera. México, Universidad Autónoma de Chapingo: 301-327.

----- comp. (1993b) La agricultura chinampanera. Compilación histórica. México, Universidad Autónoma de Chapingo. 
----- coord. (1995) Presente, pasado y futuro de las chinampas. México, CIESAS - Patronato del Parque Ecológico de Xochimilco, A.C.

Sahagún, Fray Bernardino de (1993) Primeros Memoriales. Edición facsimilar. Norman, University of Oklahoma Press.

SANDers, William T. (1993) "El lago y el volcán. La chinampa”. En: Teresa Rojas Rabiela (ed.) La agricultura chinampera. México, Universidad Autónoma de Chapingo: 129-177.

Santamaría, Miguel (1993) "Las chinampas del Distrito Federal”. En: Teresa Rojas Rabiela (ed.) La agricultura chinampera. México, Universidad Autónoma de Chapingo: 43-76.

SERRA, Mari Carmen (1995) “Terremote-Tlaltenco, una aldea lacustre de la Cuenca que no construyó chinampas”. En: Tereda Rojas Rabiela (coord.) Presente, pasado y futuro de las chinampas. México, CIESAS - Patronato del Parque Ecológico de Xochimilco, A.C.: 47-52.

Serra Puche, Mari Carmen y Castillo Mangas, María Teresa (1992) "La vida cotidiana en una chinampa xochimilca”. En: José Alcina Franch (ed.) Azteca-Mexica. Las culturas del México antiguo. México, Sociedad Estatal Quinto Centenario - Lunwerg Editores S.A.: 173-185.

VALEnCia, Rogelio (2018) "Las unidades de medida de longitud entre los nahuas prehispánicos”. En: Juan José Batalla Rosado y Miguel Ángel Ruz Barrio (coords.) El arte de escribir. El centro de México: del Posclásico al siglo XVII. México, El Colegio Mexiquense, A.C.: 117-148.

Vázquez, Karina (2016) "Ejido San Juan Ixtayopan. Oasis de cultivo en la Ciudad de México". http://hipervital.com.mx/diviertete/37-ejido-san-juan-ixtayopan-oasisde-cultivo-en-la-ciudad-de-mexico-maiz [26.06.2020]. 